\title{
Ciliary body enlargement and cyst formation in uveitis
}

Ocular Imaging Center, The New York Eye and Ear Infirmary, New York, and the Departments of Ophthalmology, The New York Eye and Ear Infirmary, New York, and New York Medical College, Valhalla, NY, USA

R C Gentile

J M Liebmann

C Tello

Z Stegman

S S Weissman

R Ritch

Correspondence to: Robert Ritch, MD,

Glaucoma Service, The New

York Eye and Ear Infirmary,

310 East 14th Street, New

York, NY 10003, USA.

Accepted for publication 28 June 1996

Ronald C Gentile, Jeffrey M Liebmann, Celso Tello, Zeev Stegman, Scott S Weissman, Robert Ritch

\begin{abstract}
Background-Acute anterior uveitis has diverse causes and systemic associations. Inflammation is predominantly localised to the iris and pars plicata. Little is known about the in vivo effects of uveitis on ciliary body anatomy.

Methods-Bilateral, high frequency, high resolution, ultrasound biomicroscopy was performed on consecutive patients with unilateral anterior uveitis to evaluate ciliary body anatomy. Imaging was repeated when possible during the clinical course. The cross sectional area of the anterior ciliary body was measured using image processing and analysis software. Measurements from the uveitic eyes were compared with the fellow eyes and the effect of treatment was evaluated.
\end{abstract}

Results-Fourteen patients were enrolled. Ultrasound biomicroscopy demonstrated a larger ciliary body cross sectional area in the uveitic eyes compared with the fellow, clinically uninvolved eyes (2.45 (SD $0.48) \mathrm{mm}^{2}$ versus $1.55(S D 0.15) \mathrm{mm}^{2},(p=$ 0.0000 ; paired $t$ test)). A ciliochoroidal effusion was present in one uveitic eye. Epithelial cysts were imaged bilaterally in four uveitic patients $(29 \%)$ and unilaterally in unaffected eyes of two uveitic patients. Ciliary body cross sectional area decreased following steroid therapy ( $p=$ 0.0001 ; paired $t$ test). New cysts were noted in three uveitic eyes during the follow up period and in none of the fellow, unaffected eyes.

Conclusion-Ultrasound biomicroscopy offers a new approach to the evaluation of anterior uveitis. The response to treatment can be evaluated objectively and therapeutic efficacy can be more easily assessed. It has the potential to help elucidate the pathophysiology and anatomical changes of this heterogeneous group of disorders.

(Br F Ophthalmol 1996;80:895-899)

Anterior uveitis is characterised by inflammation predominantly localised to the iris and pars plicata of the ciliary body, accompanied by a breakdown of the blood-aqueous barrier and increased aqueous protein and cells. Since no direct clinical pathological studies have been conducted in the acute phase of anterior uveitis, ${ }^{1}$ and since visualisation of the ciliary body in vivo is difficult with slit-lamp biomi- croscopy, little is known about the effect of acute anterior uveitis on ciliary body anatomy.

Improved imaging of the ciliary body in vivo is possible using high frequency ultrasound biomicroscopy (UBM) ${ }^{2}$ This has proved to be valuable in elucidating the anatomy and pathophysiology of a variety of anterior segment disorders. ${ }^{3-8}$ After noting ciliary body enlargement and epithelial cysts of the pars plicata in a patient with anterior uveitis, we performed this prospective pilot study to detect in vivo alterations of ciliary body appearance in anterior uveitis.

\section{Patients and methods}

After informed consent, consecutive patients with unilateral anterior uveitis underwent ophthalmic examination and UBM of both eyes. Examination included visual acuity testing, slit-lamp biomicroscopy, tonometry, gonioscopy, and indirect ophthalmoscopy. Diagnosis and classification were based on history and clinical examination using guidelines described by Tessler. ${ }^{9}$ Patients with a history of trauma, evidence of posterior uveitis, intermediate uveitis, or postoperative inflammation were excluded. Anterior chamber reaction was graded according to the method of Hogan et al. ${ }^{10}$ Laboratory evaluation, skin testing, and chest $x$ ray were performed when clinically indicated.

High resolution UBM (Zeiss-Humphrey, San Leandro, CA, USA) is based on high frequency transducers, incorporated into a $B$ mode clinical scanner. The device and technique of UBM have been reported in detail elsewhere. ${ }^{2-41112}$ Our current device uses a 50 $\mathrm{MHz}$ transducer, achieves a tissue resolution of $50 \mu \mathrm{m}$, and has a tissue penetration of $4-5 \mathrm{~mm}$. Scanning is performed with the patient in the supine position using topical anaesthesia. A 20 $\mathrm{mm}$ eye cup is placed on the eye and filled with saline solution, ${ }^{13}$ which serves as a coupling medium. The ultrasound probe is placed approximately 2-3 $\mathrm{mm}$ from the ocular surface. Fine movement of the probe is performed manually to visualise different locations of the anterior segment. Images are captured on a video printer.

The ciliary body was imaged for 360 degrees. Multiple transverse images of the anterior segment were taken in all four quadrants. When a cyst was identified it was localised to within 1 clock hour and was confirmed with a sagittal cross sectional image. The diameter of the cyst was approximated to the nearest $50 \mu \mathrm{m}$. All UBM scans were 
Table 1 Patient data and ophthalmic examination

\begin{tabular}{|c|c|c|c|c|c|c|c|}
\hline Patient & Age & Sex & Uveitic eye & Type & Cells/flare & Presumed cause & $\begin{array}{l}\text { History of } \\
\text { uveitis }\end{array}$ \\
\hline 1 & 16 & $M$ & $\mathbf{L}$ & NG & $+1 /+3$ & ID & No \\
\hline 2 & 55 & $\mathbf{F}$ & $\mathbf{R}$ & G & $+3 /+3$ & ID* & No \\
\hline 3 & 46 & $\mathrm{~F}$ & $\mathbf{R}$ & NG & $+2 /+2$ & $\mathrm{ID}^{\star}$ & No \\
\hline 4 & 47 & $\mathbf{F}$ & $\mathbf{R}$ & NG & $+2 /+1$ & ID & No \\
\hline 5 & 29 & $\mathbf{M}$ & L & G & $+3 /+3$ & ID*t & No \\
\hline 6 & 29 & M & $\bar{L}$ & NG & $+3 /+4$ & ID $\star f$ & No \\
\hline 7 & 34 & $\mathbf{M}$ & $\mathbf{L}$ & NG & $+1-2 /+1-2$ & ID & No \\
\hline 8 & 22 & $\mathbf{M}$ & $\bar{L}$ & NG & $+3 /+4$ & HLA-B27 * & Yes \\
\hline 9 & 49 & $\mathbf{M}$ & $\overrightarrow{\mathbf{R}}$ & NG & $+3 /+4$ & $\mathrm{ID}^{\star}$ & Yes \\
\hline 10 & 45 & $\mathbf{F}$ & $\mathbf{R}$ & NG & $+1-2 /+1-2$ & Colitis ${ }^{\star}$ associated & Yes \\
\hline 11 & 17 & $\mathbf{F}$ & $\mathbf{L}$ & G & $+1-2 /+1-2$ & $\mathrm{ID}^{\star}+$ & No \\
\hline 12 & 33 & $\mathbf{M}$ & L & NG & $+1 /+1$ & ID & No \\
\hline 13 & 19 & $\mathbf{M}$ & $\mathbf{R}$ & NG & $+4 /+4$ & HLA-B27* & No \\
\hline 14 & 52 & $\mathbf{F}$ & $\mathbf{L}$ & NG & $+1-2 /+1-2$ & $\mathrm{ID}^{\star}$ & Yes \\
\hline
\end{tabular}

NG = non-granulomatous; $\mathrm{G}=$ granulomatous; ID = idiopathic.

* Uveitis investigations performed.

† Positive purified protein derivative with normal chest $x$ ray.

performed by two experienced examiners (CT, ZS). Imaging was repeated during the course of the disease when patient follow up allowed.

A representative cross sectional image of the ciliary body was used to quantify ciliary body size. The cross sectional area of the anterior ciliary body on the ultrasound biomicrographs was measured using a public domain image processing and analysis program (NIH IMAGE 1.60). On a Macintosh Quadra 840AV, an 8.5 by 11 inch area consisting of five to six ultrasound biomicrographs were scanned at 300 dpi and $20 \%$ scaling on a Microtek MSF300 ZS flatbed colour/grey image scanner. Each scan was converted to a 324 kilobyte TIFF file which was imported into NIH IMAGE 1.60. The scale was calculated using the selection tool and set to 31 pixels per $\mathrm{mm}$. The anterior $2 \mathrm{~mm}$ of ciliary body was outlined using the free hand selection tool and its area was calculated using the measurement command. The external margin outlined extended $2 \mathrm{~mm}$ along the uvea-scleral interface starting anteriorly at the scleral spur. The posterior margin was constructed using a line perpendicular to the sclera. The internal and anterior margins included the ciliary processes and anterior ciliary body face. Measurement of each micrograph was performed five times and recorded as an average value in $\mathrm{mm}^{2}$.

Ciliary body sizes of the uveitic eyes before treatment were compared with the fellow, unaffected eyes, and with themselves at the same meridian after treatment. Ciliary body sizes of the uveitic eyes were correlated with the clinical examination.

\section{Results}

We examined 14 consecutive patients with unilateral anterior uveitis. Mean patient age was 35.2 (SD 13.7) years (range 16-55 years). There were eight men and six women. Six right eyes and eight left eyes were affected. The

Table 2 Cross sectional ciliary body area by group

\begin{tabular}{llll}
\hline Group & No of eyes & Area $(S D)\left(\mathrm{mm}^{2}\right)$ & Range $\left(\mathrm{mm}^{2}\right)$ \\
\hline Uveitic eyes pre-treatment & 14 & $2.45(0.48)$ & $(2.03-3.66)$ \\
Fellow eyes pre-treatment & 14 & $1.55(0.15)$ & $(1.36-1.92)$ \\
Uveitic eyes post-treatment & 11 & $1.62(0.18)$ & $(1.40-1.91)$ \\
Fellow eyes post-treatment & 11 & $1.57(0.15)$ & $(1.38-1.82)$ \\
Normal control & 15 & $1.53(0.16)$ & $(1.26-1.77)$ \\
\hline
\end{tabular}

uveitis was classified as non-granulomatous in 11 eyes (79\%) and granulomatous in three eyes (21\%). Four cases of non-granulomatous uveitis were considered recurrent by history. The remainder of the patients with nongranulomatous uveitis and all of the patients with granulomatous uveitis had no previous history of inflammation (Table 1).

Patients had varying degrees of inflammation. Mean intraocular pressure was $13.2(7.0)$ $\mathrm{mm} \mathrm{Hg}$ (range 6-28 $\mathrm{mm} \mathrm{Hg}$ ) in the affected eyes and 14.9 (3.7) (range 10-22 $\mathrm{mm} \mathrm{Hg}$ ) in the fellow eyes. Slit-lamp biomicroscopy and gonioscopy suggested the presence of a uveal cyst in one eye due to a peripheral iris elevation. Treatment consisted of topical corticosteroids and cycloplegics for all uveitic eyes with the addition of a topical $\beta$ blocker when indicated to control intraocular pressure. Two patients were treated with sub-Tenon's injections of corticosteroid. One of these was also treated with oral corticosteroids. Laboratory investigations were performed on 10 patients (71\%) and revealed HLA-B27 positivity in two patients and a positive purified protein derivative with normal chest $x$ ray in three patients (Table 1).

The cross sectional areas of the anterior ciliary body of the uveitic and the clinically unaffected, fellow eyes before treatment were 2.45 $(0.48) \mathrm{mm}^{2}$ and $1.55(0.15) \mathrm{mm}^{2}$, respectively ( $\mathrm{p}=0.0000$; paired $t$ test). Clinically unaffected eyes resembled our data base of normal controls (mean ciliary body area $1.53(0.16)$ $\mathrm{mm}^{2}$, range $1.26-1.77 \mathrm{~mm}^{2}$ ) (Table 2). Enlargement was limited to the pars plicata except for one patient (patient 13) with extension to the pars plana. Eyes with greater degrees of cell $(p=0.01)$ and flare $(p=0.03)$ reactions tended to have larger cross sectional ciliary body areas. A ciliochoroidal effusion was imaged in one uveitic eye and none of the fellow eyes.

Repeat UBM imaging was performed 1-6 months after the initiation of treatment on 11 patients. Three patients were lost to follow up. Resolution of the ciliary body enlargement or the ciliochoroidal effusion was imaged in all treated uveitic eyes (mean post-treatment cross sectional ciliary body area was $1.62(0.18)$ $\mathrm{mm}^{2}$ for the uveitic eyes and $1.57(0.15) \mathrm{mm}^{2}$ for the fellow eyes $(\mathrm{p}=0.40$; paired $t$ test)). The ciliary body was smaller in all uveitic eyes after treatment when compared with themselves before treatment $(\mathrm{p}=0.0001$; paired $t$ test). As expected, the fellow uninvolved eye did not exhibit a change in cross sectional ciliary body area during the course of the study ( $p$ $=0.57$; paired $t$ test)).

Epithelial cysts were imaged bilaterally in four patients and unilaterally in two patients (two fellow, non-uveitic eyes) before treatment. These cysts were located at the iridociliary junction (two patients), anterior ciliary body (two patients), or at both locations (two patients). Cyst diameter ranged from 150 to $1000 \mu \mathrm{m}$. Five of these patients had nongranulomatous and one had granulomatous uveitis. These cysts did not change in appearance during the course of the study. 
Three new ciliary body cysts formed (that is, cysts in areas in which they were not previously detected) in three $(27 \%)$ uveitic eyes during the follow up period. They occurred in two eyes with cysts and in one eye without any previous cysts whose fellow eye had one cyst. Two of these eyes were diagnosed with HLA-B27 associated uveitis and the other was diagnosed with colitis associated uveitis in a patient who was HLA-B27 negative. No new cysts formed in the fellow unaffected eyes during the follow up period. Of the three newly formed cysts demonstrated by UBM, two were iridociliary cysts, and one was an anterior ciliary body cyst. Their size ranged from 350 to $600 \mu \mathrm{m}$ (Table 3). There was no significant difference in the size of the ciliary body or amount of inflammation before treatment between those eyes which formed new cysts and those who did not. In a comparable series of consecutively scanned normal patients, occult ciliary body cysts were detected bilaterally in $2 / 15$ (13\%) patients.

\section{REPRESENTATIVE CASES}

Case 1 (patient 2)

A 55-year-old black woman with no past ocular or medical history presented with ciliary flush, pain, and photophobia in the right eye of 3 days' duration. Slit-lamp examination revealed $3+$ cells and flare, an open angle, and scattered posterior synechiae. The intraocular pressure was $28 \mathrm{~mm} \mathrm{Hg}$ in the right eye and $18 \mathrm{~mm} \mathrm{Hg}$ in the left eye. There was no evidence of vitreous, retinal, or choroidal inflammation in the right eye. The left eye was unremarkable. UBM demonstrated marked enlargement of the pars plicata compared with the fellow, unaffected eye (Figs 1A and B). Following medical therapy with topical prednisolone acetate $1 \%$ and cyclopentolate $1 \%$, repeat imaging demonstrated resolution of the enlargement (Fig 1C).

\section{Case 2 (patient 13)}

A 19-year-old white man with no past ocular or medical history presented with conjunctival injection in the right eye of 4 days' duration. Slit-lamp examination demonstrated $2+$ cells and flare. Intraocular pressure was $6 \mathrm{~mm} \mathrm{Hg}$ with anterior vitreous cells and normal dilated ophthalmoscopy. Despite intensive topical therapy with prednisolone acetate $1 \%$, the inflammation increased to $4+$ cells and flare and he developed a spontaneous hyphaema.
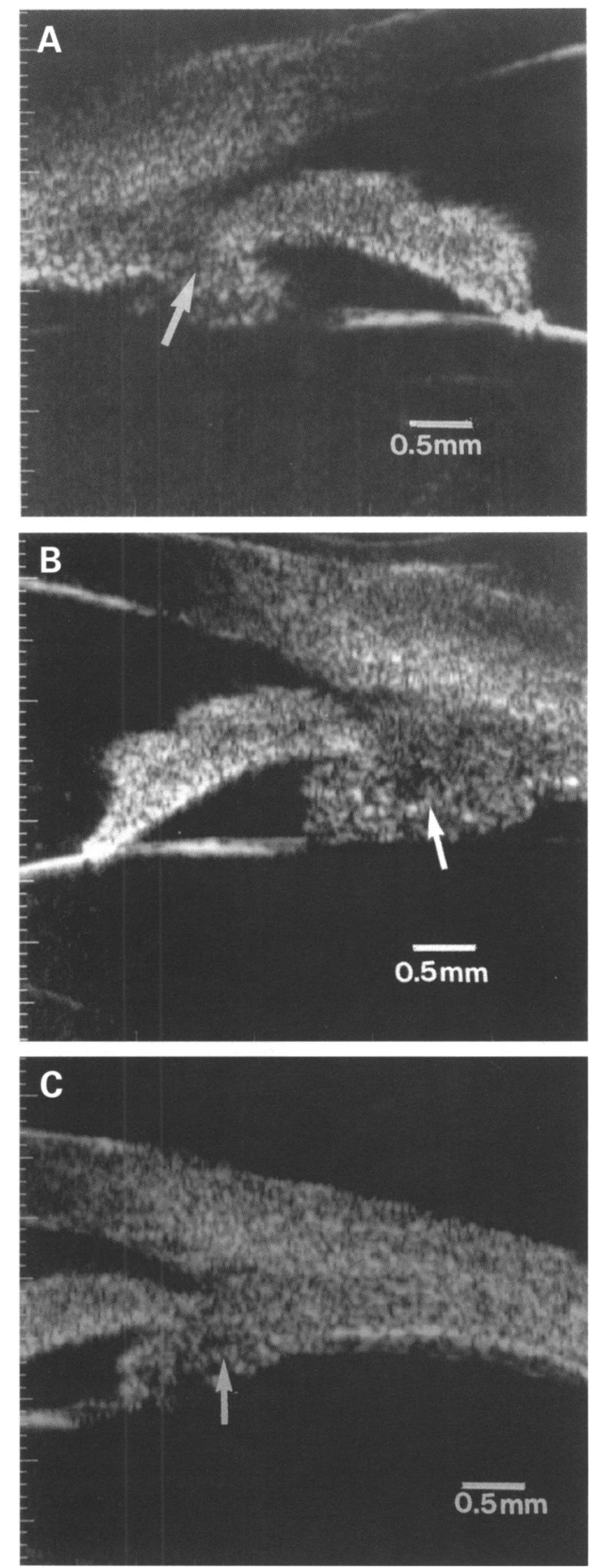

Figure 1. (A) Sagittal view of a normal ciliary body (arrow) in the unaffected eye. (B) Enlarged ciliary body (arrow) in the uveitic eye before treatment. (C) Resolution of ciliary body enlargement (arrow) following treatment.

Table 3 Ciliary body cysts

\begin{tabular}{|c|c|c|c|c|c|c|c|c|c|}
\hline \multirow[b]{2}{*}{ Patient } & \multicolumn{3}{|c|}{ Uveitic eye (pre-treatment) } & \multicolumn{3}{|l|}{ Fellow eye } & \multicolumn{3}{|c|}{$\begin{array}{l}\text { Uveitic eye (post-treatment } \\
\text { formation) }\end{array}$} \\
\hline & Location & Clock hour & Size $(\mu m)$ & Location & Clock hour & Size $(\mu m)$ & Location & Clock hour & Size $(\mu m)$ \\
\hline 7 & ACB & $6: 00$ & 700 & $\begin{array}{l}\mathrm{ACB} \\
\mathrm{ACB}\end{array}$ & $\begin{array}{l}7: 00 \\
7: 00\end{array}$ & $\begin{array}{l}700 \\
250\end{array}$ & None & NA & NA \\
\hline 8 & $\begin{array}{l}\text { ACB } \\
\text { ICJ } \\
\text { ICJ }\end{array}$ & $\begin{array}{l}6: 00 \\
5: 00 \\
12: 00\end{array}$ & $\begin{array}{l}700 \\
250 \\
400\end{array}$ & $\begin{array}{l}\text { ICJ } \\
\text { ICJ } \\
\text { ICJ }\end{array}$ & $\begin{array}{l}7: 00 \\
10: 00 \\
12: 00\end{array}$ & $\begin{array}{r}700 \\
1000 \\
300\end{array}$ & ICJ & $9: 00$ & 500 \\
\hline $\begin{array}{l}10 \\
11 \\
12\end{array}$ & $\begin{array}{l}\text { ACB } \\
\text { None } \\
\text { ICJ }\end{array}$ & $\begin{array}{l}9: 00 \\
\text { NA } \\
3: 30\end{array}$ & $\begin{array}{c}1000 \\
\text { NA } \\
800\end{array}$ & $\begin{array}{l}\text { ICJ } \\
\text { ICJ } \\
\text { ICJ } \\
\text { ICJ }\end{array}$ & $\begin{array}{l}4: 00 \\
9: 00 \\
7: 00 \\
11: 00\end{array}$ & $\begin{array}{l}200 \\
300 \\
150 \\
800\end{array}$ & $\begin{array}{l}\text { ICJ } \\
\text { None } \\
\text { None }\end{array}$ & $\begin{array}{l}5: 00 \\
\text { NA } \\
\text { NA }\end{array}$ & $\begin{array}{l}350 \\
\text { NA } \\
\text { NA }\end{array}$ \\
\hline 13 & None & NA & NA & ACB & $3: 00$ & 250 & ACB & $9: 00$ & 600 \\
\hline
\end{tabular}

ACB = anterior ciliary body; ICJ = iridociliary junction; NA = not applicable. 

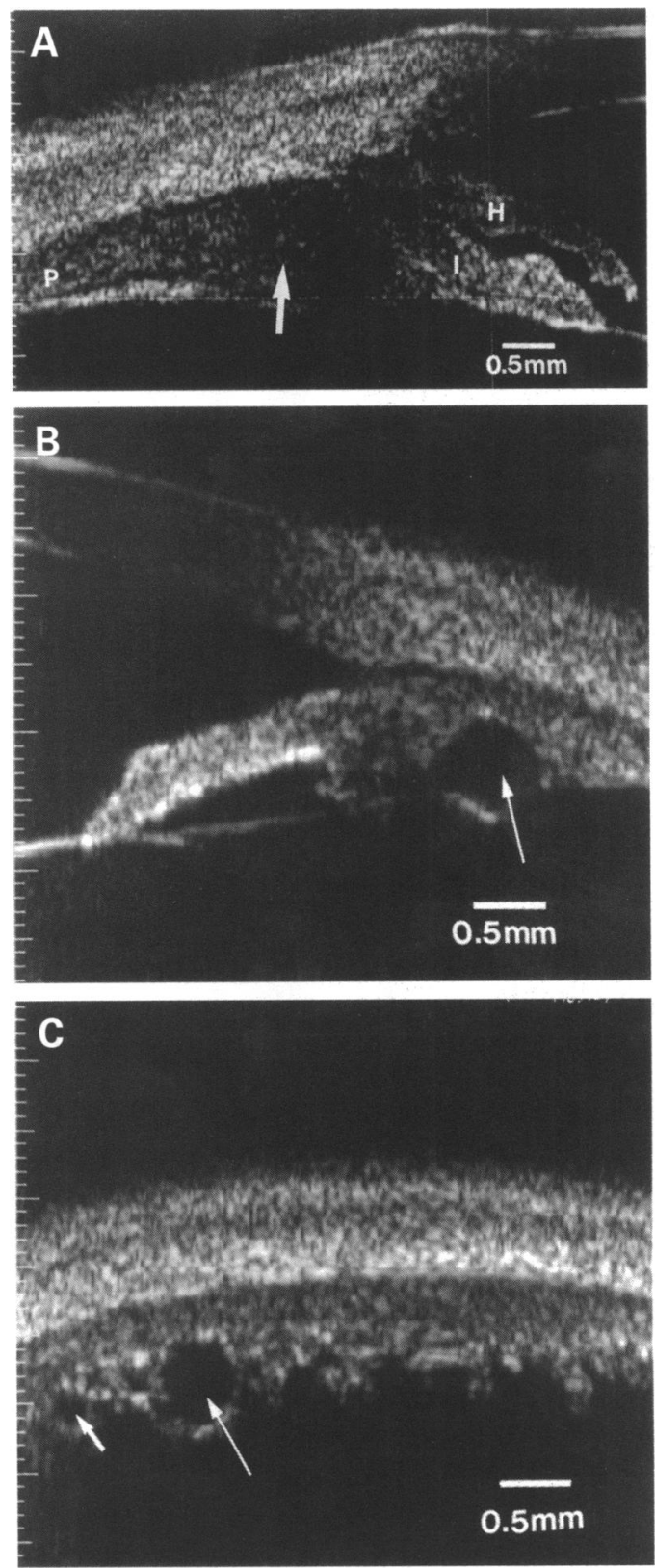

Figure 2 (A) Sagittal view of massive enlargement of the ciliary body (arrows) involving the pars plana $(P)$ with associated hyphaema $(H)$ in the uveitic eye. The iris is visible (I). (B) A new ciliary body cyst (arrow) has formed after treatment has begun. (C) Transverse section showing two small cysts (arrows) on the anterior ciliary body in the fellow eye.

UBM demonstrated massive ciliary body enlargement with interzonular debris and a partially contracted blood clot in the anterior chamber (Fig 2A). No cysts were identified. Repeat UBM imaging after administration of periocular corticosteroids demonstrated resolution of the ciliary body swelling and the formation of a single large anterior ciliary body cyst (Fig 2B). The fellow eye had two small pars plicata cysts at 3 o'clock (Fig 2C). The patient was HLA-B27 positive.

\section{Case 3 (patient 14)}

A 52-year-old Hispanic woman presented with recurrent anterior uveitis in the left eye of 3 days' duration. A similar episode had occurred 2 years earlier. Slit-lamp examination revealed 1-2+ cells and flare. The intraocular pressure was $22 \mathrm{~mm} \mathrm{Hg}$ and the angle was wide open.
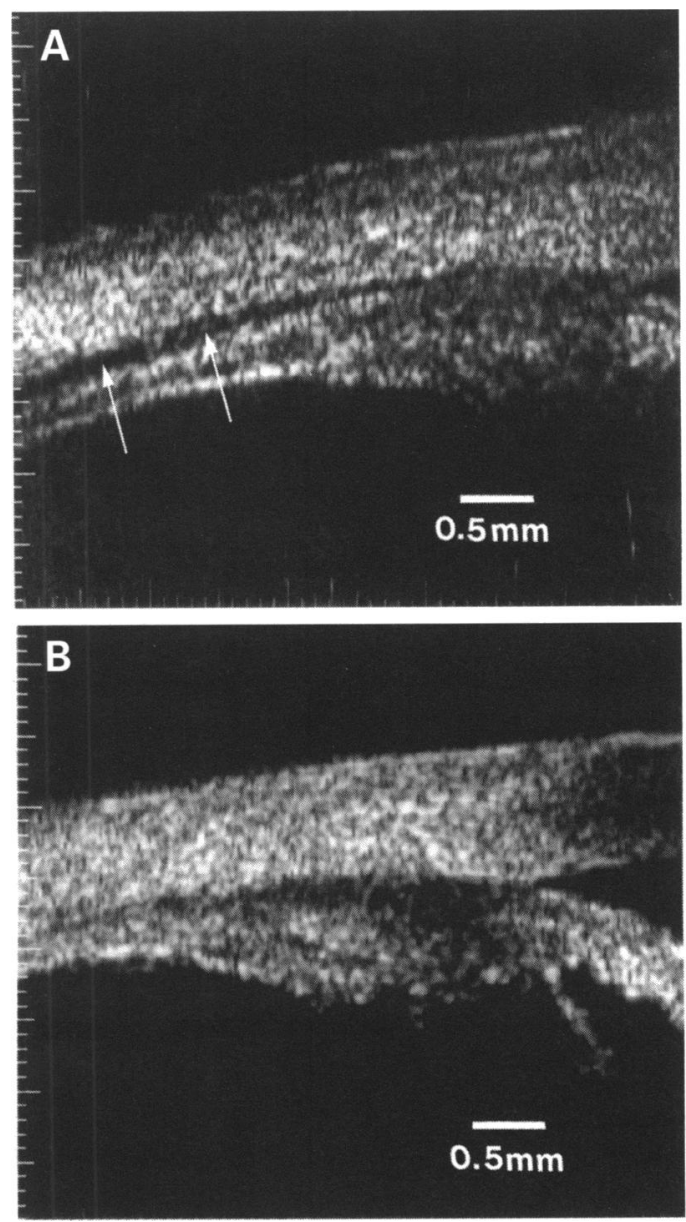

Figure 3 (A) Sagittal view of low lying ciliochoroidal effusion (small arrows). (B) Resolution of the effusion following treatment.

The posterior segment was normal. UBM demonstrated minimal ciliary body enlargement with a shallow ciliochoroidal effusion in the uveitic eye (Fig 3A). Repeat UBM after treatment demonstrated resolution of the effusion (Fig 3B).

\section{Discussion}

Uveitis has diverse causes and systemic associations. The most widely used system of classification is based on the anatomical location of inflammation within the eye. Anterior uveitis, the most common form, can be subdivided clinically into iritis, iridocyclitis, and anterior cyclitis. ${ }^{14}$ Very little is known about the pathology of acute anterior uveitis, with no clinical pathological studies in the acute phase having been conducted. ${ }^{1}$ Our study is the first to report in vivo alterations in ciliary body anatomy associated with uveitis.

Ciliary body enlargement occurred in all eyes with uveitis and was directly related to the amount of inflammation. This most probably represents stromal oedema caused by extravasation of plasma and infiltration of acute inflammatory cells from vascular beds within the ciliary body. Consistent with the clinical impression of the location of inflammation, enlargement was limited to the pars plicata in all eyes except one. The exception was a patient (no 13) with a massively enlarged pars plicata, severe intraocular inflammation, and a thickened pars plana. 

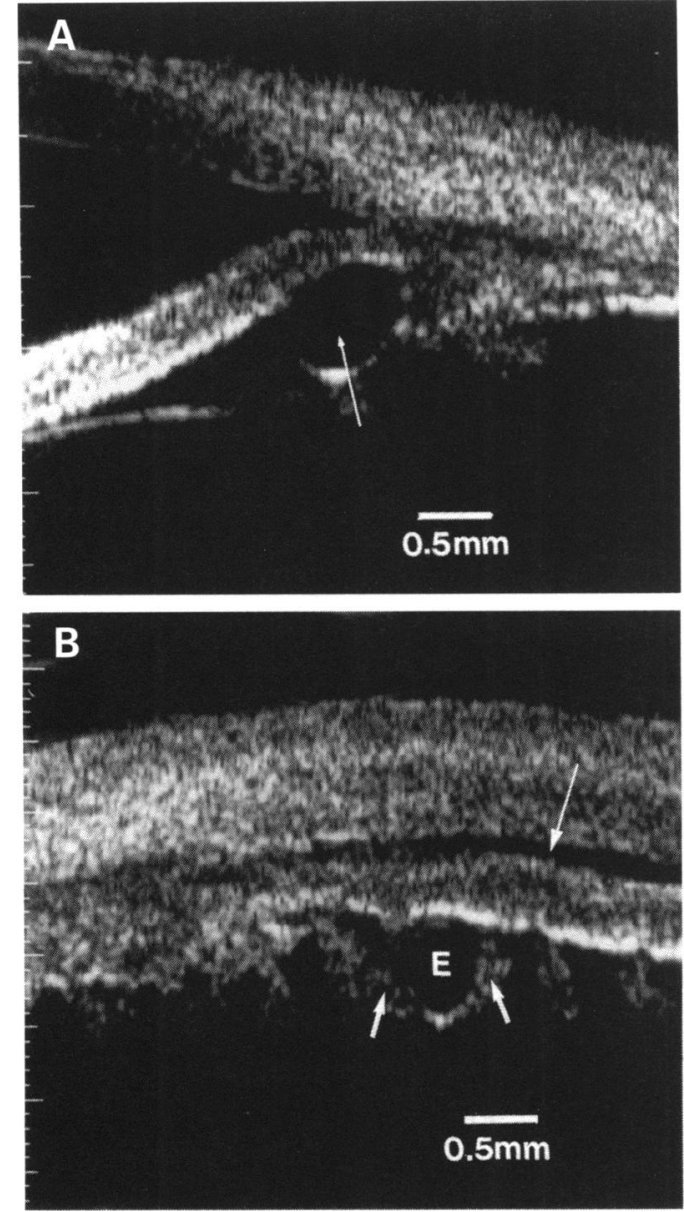

Figure 4 (A) Typical cyst (arrow) at the iridociliary junction. $(B)$ Cyst $(E)$ in transverse section among the ciliary processes (small arrows). The angle recess is visible (arge arrow).

UBM imaged resolution of the ciliary body enlargement in all uveitic eyes and resolution of a small ciliochoroidal effusion in one eye after treatment. In addition to detecting small subclinical effusions, UBM offers a new possible quantitative tool in the evaluation of uveitis.

UBM imaging on a video monitor permitted visualisation of all the ciliary processes and detection of cysts during each examination with accurate assessment of number and location. Ultrasonographically lucent areas consistent with a diagnosis of epithelial cysts were found in both the uveitic and fellow nonuveitic eye. The majority of ciliary body cysts were bilateral and were located within the posterior iris and ciliary body epithelium at the iridociliary junction or anterior ciliary body (Fig 4). Although these cysts have been reported to occur primarily without inflammation, ${ }^{12} 15-17$ some cases have been described in eyes with inflammation. ${ }^{1516}$

Three uveitic eyes in the present study showed evidence of new cyst formation, the significance of which is unclear. It is possible that eyes with inflammation have a predisposition to cyst formation. We postulate that cyst formation may occur as fluid enters the interepithelial space of the posterior iris and ciliary body. This may become more pronounced as ciliary body enlargement subsides, as evidenced by the formation of new cysts in three of our patients.

In summary, UBM offers a new approach to the evaluation of anterior uveitis. The response to treatment can be evaluated objectively and therapeutic efficacy can be more easily assessed. UBM has the potential to help elucidate the pathophysiology and anatomical changes of this heterogeneous group of disorders.

This work was supported in part by The Glaucoma Foundation, New York; awards in memory of Mary E and Alexander $P$ con, N (to CT) and Herbert Tenzer (to ZS), by The New York Hirsch (to CT) and Herbert Tenzer (to ZS), by The New York Glaucoma Research Institute, New York, The Fight For Sight Research Division of Prevent Blindness America, New York; and The New York Eye and

thalmology Research Fund.
Presented in part at the Annual Meeting of the American Academy of Ophthalmology, Chicago, Illinois, 14-15 Novem ber 1993 .

The authors have no financial interest in the ultrasound biomicroscope.

1 Green WR. Uveal tract. In: Spencer WH, ed. Ophthalmic pathology: an atlas and text book. 3rd ed. Philadelphia: W B Saunders, 1986;3:1996-7

2 Pavlin CJ, Sherar MD, Foster FS. Subsurface ultrasound microscope imaging of the intact eye. Ophthalmology 1990; 97:244-50.

3 Pavlin CJ, Easterbrook M, Harasiewicz K, Foster FS. An ultrasound biomicroscopic analysis of angle-closure glaucoma secondary to ciliochoroidal effusion in IgA nephropathy. Am $₹$ Ophthalmol 1993;116:341-5.

4 Pavlin CJ, Ritch R, Foster FS. Ultrasound biomicroscopy in Pavlin CJ, Ritch R, Foster FS. Utrasound biomicroscopy in
plateau iris syndrome. Am $f$ Ophthalmol 1992;113:390-5.

5 Tello C, Chi T, Shepps G, Liebmann J, Ritch R. Ultrasound biomicroscopy in pseudophakic malignant glaucoma. Ophthalmology 1993;100:1330-4.

6 Pavlin CJ, Harasiewicz K, Sherar MD, Foster FS. Clinical use of ultrasound biomicroscopy. Ophthalmology 1991;98: 287-95.

7 Pavlin CJ, Rootman D, Arshinoff S, Harasiewicz K. Determination of haptic position of transsclerally fixated posterior chamber intraocular lenses by ultrasound biomiposterior chamber intraocular lenses by ultrasound

8 Potash S, Tello C, Liebmann JM, Ritch R. Ultrasound biomicroscopy in pigment dispersion syndrome. Ophthalmology 1994;101:332-9.

9 Tessler HH. Classification and symptoms and signs of uveitis. In: Tasman W, Jaeger EA, eds. Duane's clinical ophthalmology, rev ed. New York: Harper Row, 1991;4 (chapter 32):1-10.

10 Hogan MH, Kimura SJ, Thygeson P. Signs and symptoms of uveitis: I. Anterior uveitis. Am $\mathcal{f}$ Ophthalmol 1959;47: 155-70.

11 Sherar MD, Foster FS. A $100 \mathrm{MHz}$ PVDF ultrasound microscope with biological applications. Acoust Imaging 1988;16:511-20.

12 Pavlin CJ, McWhae JA, McGowan HD, Foster FS. Ultrasound biomicroscopy of anterior segment tumors. Ophthalmology 1992;99:1220-8.

13 Tello C, Liebmann J, Ritch R. An improved coupling medium for ultrasound biomicroscopy. Ophthalmic Surg 1994;25:410-1

14 Kanski J. Uveitis, A colour manual of diagnosis and treatment. London: Butterworths, 1987.

15 Duke-Elder S, Perkins ES. Cysts and tumors of the uveal tract. In: Duke-Elder S, ed. System of ophthalmology. St Louis: Mosby, 1977;9:754-65.

16 Shields JA, Kline MW, Augsburger JJ. Primary iris cysts: a review of the literature and report of 62 cases. $B r f$ Ophthalmol 1984;68:152-66.

17 Vela A, Rieser JC, Campbell DG. The heredity and treatment of angle-closure glaucoma secondary to iris and ciliary body cysts. Ophthalmology 1984;91:332-7. 